\title{
Impregnation of Crushed Stone with Bitumenous Compounds Using Propane/Butane Impregnation Process Carried out in Supercritical Fluid Conditions
}

\author{
Farid M. Gumerov', Mansur I. Farakhov², Vener F. Khayrutdinov², Farizan R. Gabitov ${ }^{1}$, \\ Zufar I. Zaripov' ${ }^{2}$, Inar Sh. Khabriyev ${ }^{1}$, Talgat R. Akhmetzyanov ${ }^{1}$ \\ ${ }^{1}$ Federal State Budgetary Educational Institution of Higher Professional Education, Kazan National Research \\ Technological University, Kazan, Russia \\ ${ }^{2}$ Limited Liability Company Engineering-Promotional Center "Inzhekhim”, Kazan, Russia \\ Email: gum@kstu.ru
}

Received 9 August 2014; revised 15 September 2014; accepted 9 October 2014

Copyright (C) 2014 by authors and Scientific Research Publishing Inc.

This work is licensed under the Creative Commons Attribution International License (CC BY).

http://creativecommons.org/licenses/by/4.0/

(c) () Open Access

\section{Abstract}

An efficient technology of impregnation of carbonate crushed stone by oil-product based on SCFimpregnation process usage with propane/butane solvent was developed. Regular impregnation throughout the volume of crushed stone sample is achieved. As a result of the appliance of proposed technology, the humidity of the treated crushed stone samples decreased down to $0.54 \%$.

\section{Keywords}

Impregnation, Carbonate Crushed Stone, Propane, Butane, Supercritical Fluid

\section{Introduction}

During the last few years, specialists of road construction industry pay increasingly more attention to investigating the possibilities of reinforcing and strengthening the low-durable materials (sand-and gravel mixtures, lowdurable stone materials, grounds, etc.) by various reinforcing substances of poly-functional action of organic and non-organic origin.

At present, there are already papers in which the authors suggest various versions of reinforcing the carbonated crushed stone [1]-[3]. For example, the authors of paper [1] suggest the following procedure of impregnation of the crushed stone: the process is carried out at room temperature and under the excess pressure of 0 to 6.0

How to cite this paper: Gumerov, F.M., et al. (2014) Impregnation of Crushed Stone with Bitumenous Compounds Using Propane/Butane Impregnation Process Carried out in Supercritical Fluid Conditions. American Journal of Analytical Chemistry, 5, 945-956. http://dx.doi.org/10.4236/ajac.2014.514102 
MPa using the sleeper-impregnating composition (mineral-coal oil, shale oil, or their mixture of various compositions). The duration of the process is from 120 to 300 seconds and implies the consequent treatment of the crushed stone with molten bitumen (3\% of the mass of the crushed stone) till reaching the uniform enveloping of the road material. The use of this method of treatment enables to reduce the water-absorption of the crushed stone by 2.23 - 3.96 times.

In paper [2] the impregnation of the limestone crushed stone is carried out using bitumen melted under $110^{\circ} \mathrm{C}$ $120^{\circ} \mathrm{C}$ in the presence of product of the interaction of boric acid, diethanolamine and mixture of vegetable oils' fatty acids (fractions $C_{6}-C_{20}$ ) with the reagents' mole ratio of 1:3:(0.5 - 2.5) taken in total of $0.5 \%-2.0 \%$ of the mass of the bitumen. In this case the consumption of the bitumen was $1.5 \%-2.0 \%$ of the limestone crushed stone's mass. This resulted in the increased fungus resistance and the reduced water absorption to $0.9 \%$.

In paper [3] the reinforcement of the crushed stone made of low-durable carbonate rocks is carried out by impregnating it with melted sulphur. Sulphur as an impregnating material possesses a number of positive properties: the relatively low temperature of melting $112.8^{\circ} \mathrm{C}-119.3^{\circ} \mathrm{C}$, low viscosity of the melt $\left(6.5 \times 10^{-3} \mathrm{~Pa} \cdot \mathrm{s}\right)$, sufficient mechanical strength after the crystallization, the hydro-repellence, high water- and chemical stability. The sulphur melt is able to penetrate rather deeply in pores of various diameters including capillaries, and in the process of crystallization during the subsequent cooling to unite strongly with the matrix. In this case the construction material with the inter-penetrating structure is formed. As a result of impregnating the carbonate crushed stone with the melted sulphur a gradient under-the-surface layer appears on the surface of the grains, having a more solid structure preventing the penetration of water in the porous space of the middle "nucleus" and its reliable capsulation is formed. This fact of the uneven impregnation-in this case of the crushed stoneis typical for all the approaches described above that use the liquid-phase solution as an impregnation material. It is due to this liquid condition such shortcoming features are typical from the point of view of the possibility of penetrating into the high-porosity matrixes including the high viscosity and low diffusion abilities, the presence of the surface tension and the capillary effect. As an example, one can list a wide range of heterogenous catalysts that are traditionally synthesized using the method of the liquid-phase impregnation. Such catalysts are referred to the category of crust catalysts and have the concentration of active centers only in thick surface layer of the catalyst carrier and this feature is considered as a rule as one of their shortcomings [4]-[6].

The crushed stone modified in this way splits up intensively in the process of road construction and during the first years of operation thus resulting in the exposition of its inner part that was not treated. This leads to the increased water absorption and the loss of physical-mechanical properties of the crushed stone thus minimizing the effect of the modification that was performed earlier.

Therefore, the elaboration of new technologies of reinforcing the crushed stone made of low-durable carbonate rocks is an urgent task. Its solution will enable to improve the quality of the crushed stone and to obtain a highly effective material for road construction.

Thus the main target of this investigation is elaboration of innovative technology of the uniform going all the way through impregnation of the crushed stone ensuring the reduction of water absorption even under the conditions of the fragmentation of the crushed stone in the process of operation. It is suggested to use as the basis of this technology the super-critical fluid impregnation process (the process of impregnation using the solvent in the super-critical fluid state [7]) by impregnating the crushed stone by the de-asphaltizer that is obtained in the process of the liquid propane/butane extraction from the crude oil residues.

The SCF technologies based on the use of operating mediums in sub- and SCF states nowadays represent one of the prospective innovative scientific-technological directions. The SCF that simultaneously combine the advantages of gaseous and liquid states of operating mediums considerably intensify heat and mass transfer properties. In particular the SCF mediums possess the lowest values of kinematic viscosity $(v=\eta / \rho)$ that are by $1-2$ orders lower than values typical for liquid organic solvents. The presence of kinematic viscosity in denominators of the Grasgof and Reinolds numbers indicates the considerable intensity of the free and forced forms of movement in the super-critical fluid mediums. The diffusion (binary diffusion and self-diffusion) of the super-critical fluid mediums exceeds by 1 - 2 levels the similar index for the same liquid organic solvents [10]. In the case of super-critical fluid mediums, there is no phase interface, the surface tension and, accordingly, the capillary effect. All this together determines their high penetrating ability into porous structures and the significant perspectives including those regarding the target of crushed stone impregnation. The effectiveness of this approach was many times confirmed both by multiple research works [6]-[13] and industrial realizations [7] [9] [14]-[17]. 


\section{Theoretical Analysis}

Taking the SCF impregnation process being a part of the complex technology as a more innovative and less investigated the authors concentrate their attention on technological fundamentals of this particular process.

One can mention the following as key issues deserving more intent attention:

1) SCF mediums, their properties and validity of their application as solvents within the framework of the task of the treatment of high-porosity matrixes;

2) Characteristics of phase equilibriums of the potential solvent (propane/butane mixture) intended for use in the SCF state;

3) Characteristics of the change of the solubility of the impregnation material in the propane/butane mixture within the range of the change of the phase state of the solvent from liquid to SCF state.

The first issue was described conceptually in the Introduction and is presented in detail in the profile literature. One can add to the above-mentioned literary sources papers [18]-[23].

The importance of knowing the characteristics of the phase equilibrium of the propane/butane mixture in this particular case is determined by various phase states of the extragent/solvent in the discussed processes. The authors would like to remind that one discusses the liquid extracting deasphaltization of the crude oil residue during the first stage and the impregnation of the carbonate crushed stone with deasphaltizer using the same propane/butane solvent but in the super-critical fluid state during the second stage of the complex technology. The authors point out that these characteristics of the phase equilibrium provide the most distinctive picture regarding the parameters of boundaries of various phase states. Figures 1-4 represent the diagrams of the phase equilibrium of the propane/butane mixture [24]-[26].

In their investigations the authors used the propane/butane mixture [27] containing $75 \%$ of propane and $25 \%$ of butane as the liquid extragent (the stage of deasphaltization) and the super-critical fluid solvent (the stage of super-critical fluid impregnation). The critical parameters of the propane and butane according to [24] are characterized by the following values: propane: $\mathrm{T}_{\mathrm{cr}}=369.82 \mathrm{~K}, \mathrm{P}_{\mathrm{cr}}=4.247 \mathrm{MPa}$; butane $\mathrm{T}_{\mathrm{cr}}=425 \mathrm{~K}, \mathrm{P}_{\mathrm{cr}}=3.797$ MPa.

The high solubility of the de-asphaltizate in the liquid propane/butane mixture is the main factor determining the effectiveness of the extraction process during the first stage of the complex technology and the rapid reduction of the solving ability of the same propane/butane mixture in respect of the same de-asphaltizate after converting the solvent from the liquid state into the super-critical fluid state must take place at the second stage of

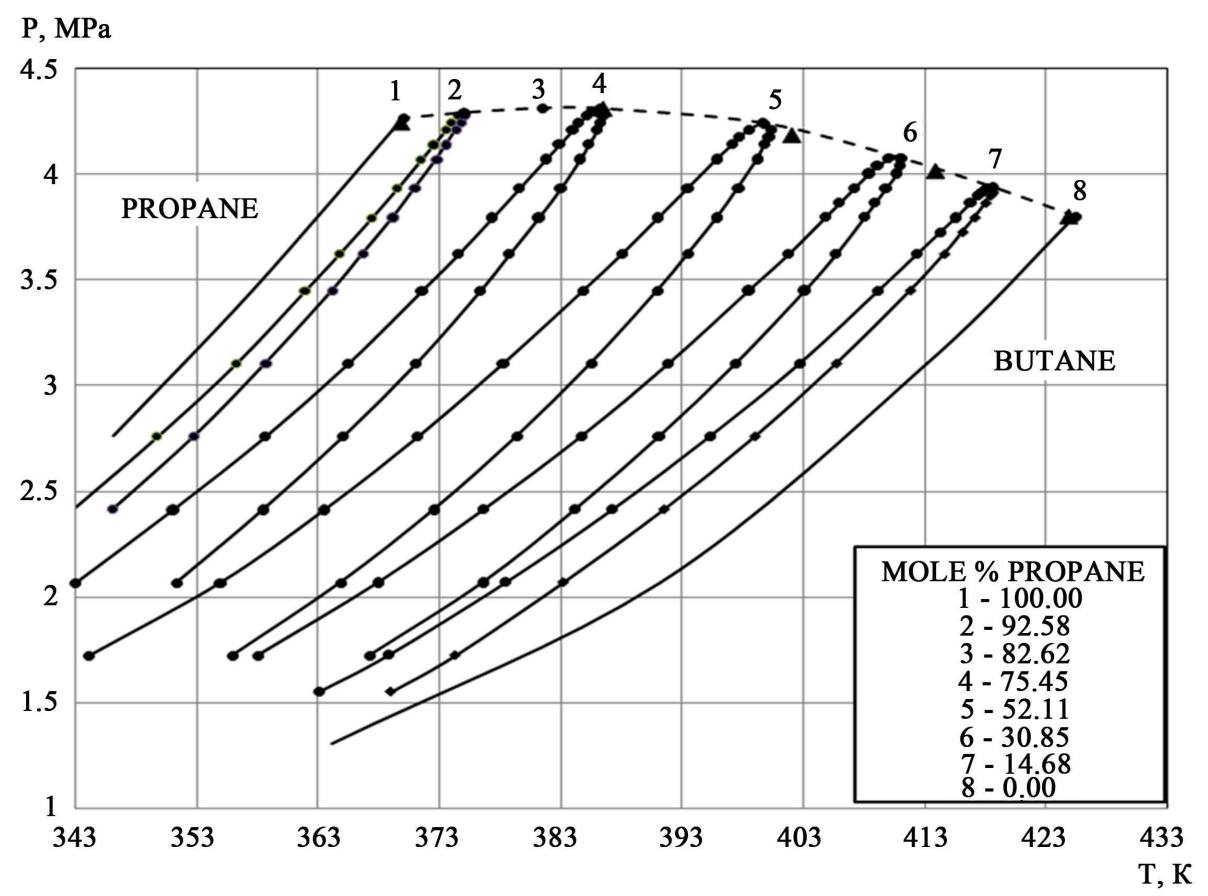

Figure 1. P-t diagram of the phase equilibrium of the propane/butane mixture [24] [26]. 


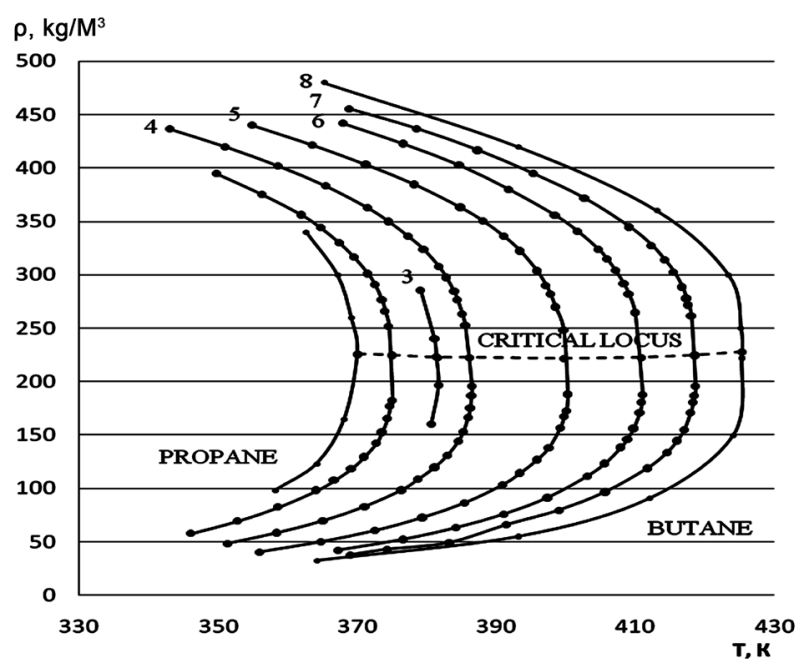

Figure 2. $\rho$-t diagram of the phase equilibrium of the propane/butane mixture [24].

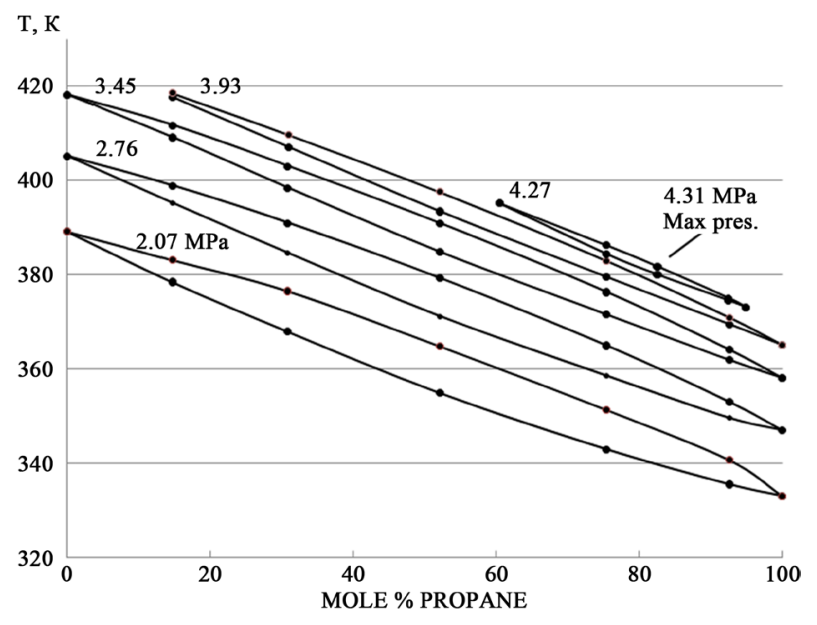

Figure 3. t-x diagram of the phase equilibrium of the propane/butane mixture [24].

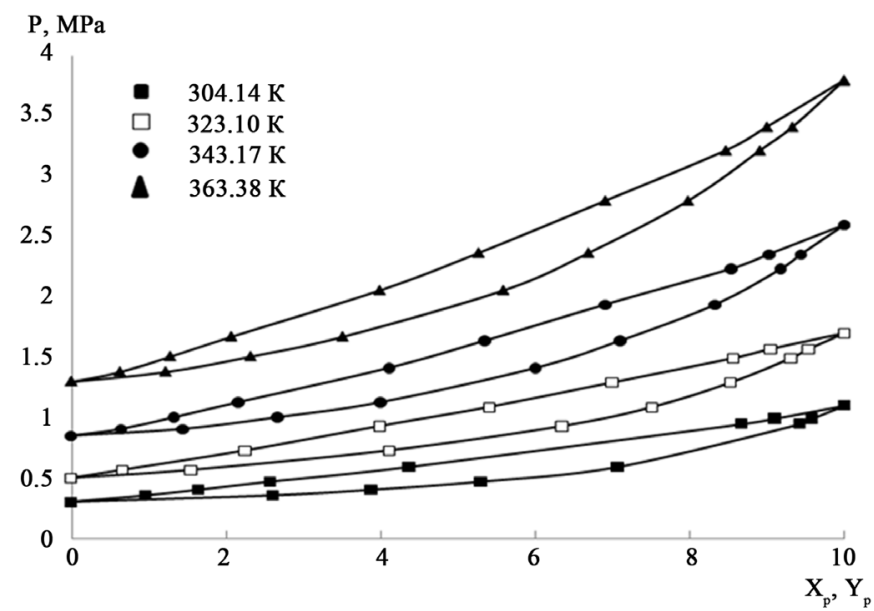

Figure 4. P-x diagram of the phase equilibrium of the propane/butane mixture [25]. 
the discussed technology. This last state is the basis of the mechanism of the impregnation process and must be realized in the high pressure impregnation chamber.

The key problem of solubility and especially in super-critical fluid solvents is the subject of intensive investigations of the last 2 - 3 decades [7] [9] [28]-[30] including the research in the direction of elaborating new experimental methods and methodologies [31] of investigating this important thermo-dynamic characteristics.

Three main factors determining the solubility of a substance in one or another solvent include: the nature of the substance to be dissolved and of the solvent, their aggregate states and thermo-dynamic conditions.

Two factors working in opposite way determine the character of the change of the solubility of a substance in the super-critical fluid solvent. On the one side, the temperature growth leads to the increase of the pressure of saturated vapours of the solved substance and as the result its concentration in the phase of the solvent increases meaning that the solubility increases as well. On the other side, the growth of the temperature (at $\mathrm{P}=$ Const) leads to the reduction of the density of the super-critical fluid solvent. And this determines the reduction of the solving ability of the super-critical fluid medium or the solubility of the substance in the super-critical fluid.

Figure 5 and Figure 6 show the character of the change of the solubility of the model substance and naphthalene $\left(\mathrm{C}_{10} \mathrm{H}_{8}\right)$ on the isobars in the regions of the liquid, sub-critical and super-critical fluid states of the sol-

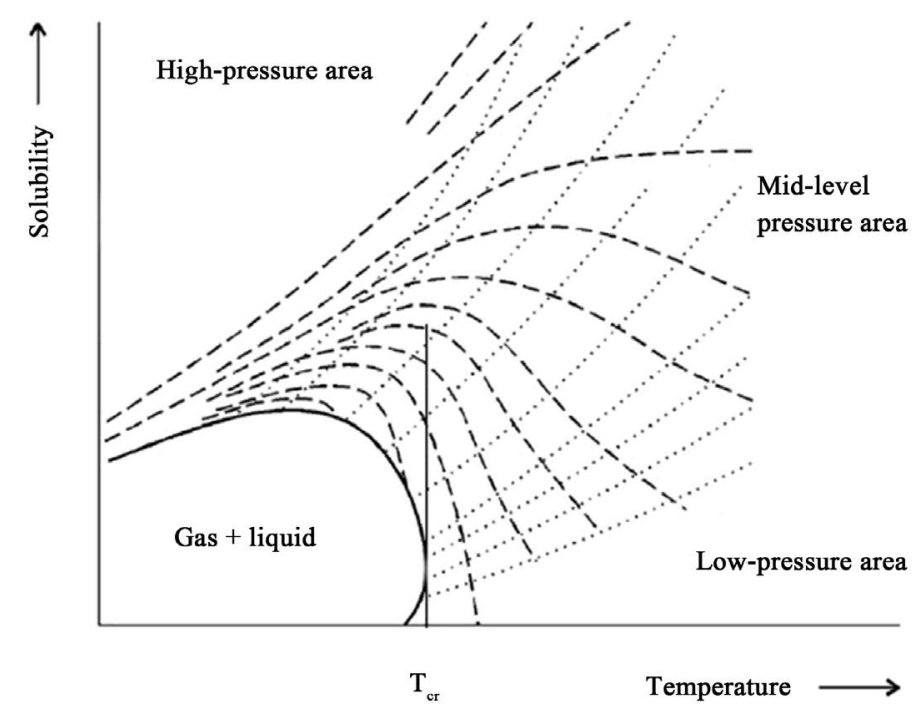

Figure 5. The character of the change of the solubility of the model substance on isobars in the regions of liquid, sub-critical and supercritical fluid states of the solvent [30].

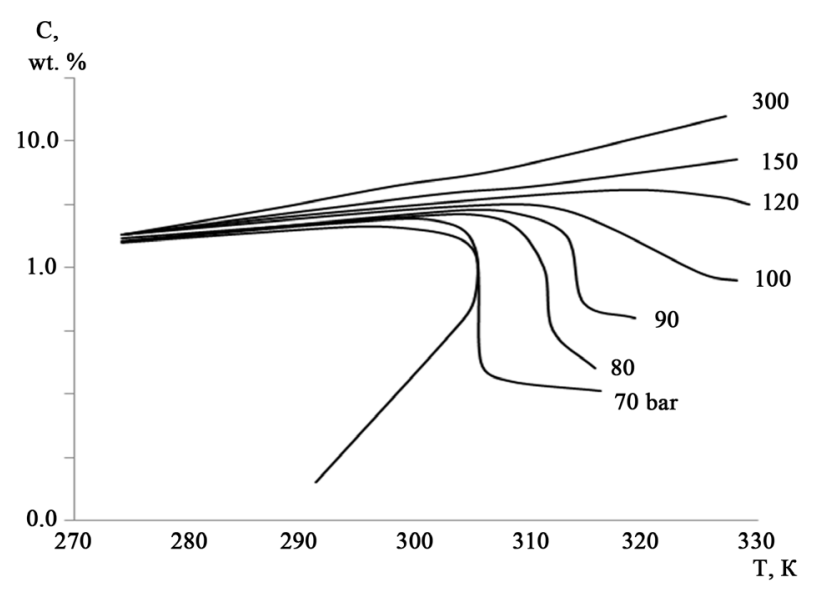

Figure 6. The character of the change of the solubility of naphthalene in carbon dioxide on isobars in the regions of liquid, subcritical and super-critical fluid states of the solvent [32]. 
vent. One should pay attention to the fact that in the region of the super-critical fluid state at the pressures that are lower than the value of the pressure in the first crossover point $\mathrm{P}^{*}$ (Figure 7), when the temperature increases one would observe the drastic reduction of the solubility and this is the essence of the mechanism of the super-critical fluid impregnation process realized in the dynamic regime. The authors remind that the static regime of the super-critical fluid impregnation process presumes the cyclic-periodical character of the treatment of the solid matrix. In this case within the framework of each cycle the matrix is kept for some time (15 - 20 minutes) in the medium of the super-critical fluid solution of the impregnation material and only after that the pressure is drastically reduced (sometimes not completely) in order to reduce the dissolving ability of the solvent and to initiate the fall-out of the impregnation material in the solid matrix. The dynamic regime presumes the continuous circulation of the super-critical fluid solution of the impregnation material through the impregnation vessel at a certain permanent pressure $\mathrm{P}<\mathrm{P}^{*}$ with the abrupt increase of the temperature in the area of location of the matrix being impregnated (in our case it is the crushed limestone). Thus the characteristics of the phase equilibrium and the character of the change of the solubility in the wide range of the change of parameters and the phase state of the propane/butane mixture determine the regime conditions of the execution of the liquid extraction (I) and the super-critical fluid impregnation (II) processes: (I): $\mathrm{P}_{\mathrm{cr}} \leq \mathrm{P}_{\mathrm{I}}<\mathrm{P}^{*}, \mathrm{~T}_{\mathrm{I}}<\mathrm{T}_{\mathrm{cr}}$; (II): $\mathrm{P}_{\mathrm{II}}=\mathrm{P}_{\mathrm{I}}, \mathrm{T}_{\mathrm{II}}>\mathrm{T}_{\mathrm{cr}}$. According to [26] for the above-given composition of the propane/butane mixture intended for use the critical parameters have the following values: $\mathrm{T}_{\mathrm{cr}}=386 \mathrm{~K}\left(\sim 113^{\circ} \mathrm{C}\right) ; \mathrm{P}_{\mathrm{cr}}=4.31 \mathrm{MPa}$. As for the value of the pressure in the first crossover point, for example, for naphthalene (Figure 6) with carbon dioxide as the solvent it has the value of about 130 bars. The authors remind that when the values of the pressure are higher or lower in the crossover point (irrespective whether it is the first or the second) the direction of the change of the solubility becomes absolutely opposite when the temperature increases. Besides, the naphthalene is a pure hydrocarbon whereas the deasphaltizer is a mixture. One can make approximate assessments of the value of the pressure in the first crossover point only on the basis of reference data for solubility for main components of this mixture. The practical absence of experimental data for solubility of substances in the propane/butane mixture in the super-critical fluid state induced the authors of this investigation to an indirect experimental assessment of this parameter. The importance of notions regarding the value of this parameter is plain and evident. If the condition $\mathrm{P}_{\mathrm{II}}<\mathrm{P} *$ is not fulfilled when the temperature rises the solubility will increase and the sedimentation will be absent and actually the impregnation process. And finally the analysis submitted for the characteristics of the pure solvent and not the solution is conditioned by the fact that super-critical fluid solutions are, as a rule, diluted and the presence of the dissolved substance does not render any significant influence on the values of critical parameters.

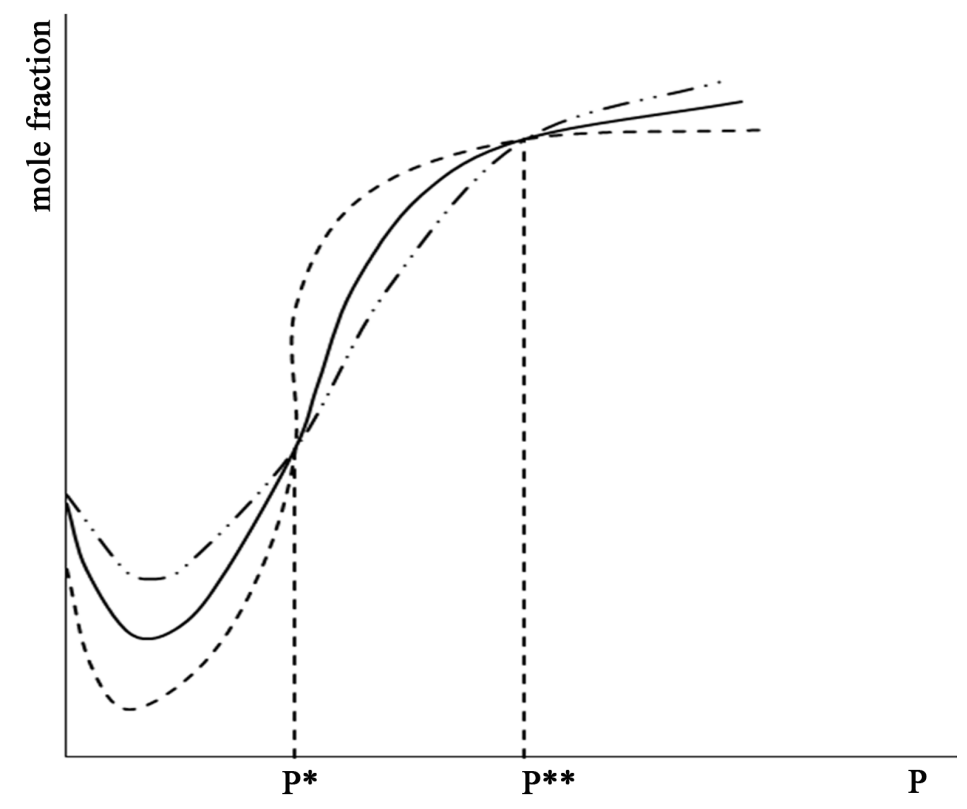

Figure 7. The character of the change of the solubility of the model substance in the on isobars in the super-critical fluid solvent and the crossover points [33]. 


\section{Experimental}

\subsection{Materials}

Crushed limestone was used as a raw material, mesh size 20 - $40 \mu \mathrm{m}$ [34] from Saltykovsky field in Republic of Tatarstan. Quantity chemical analysis is presented in Table 1.

Deasphaltizate was used as an impregnation material, which had been gained from the heavy oil residue of conversion process of high-viscosity oil from Ashalchinsk place by thermal-steam effect method [35] and propan/butanoicdeasphaltizing [36].

\subsection{Set Description}

For complex technology practice the experimental set was created, which is shown on Figure 8.

The set includes pressure creation and maintenance system and control and temperature regulation system. Pressure creation system consists of balloon with $\mathrm{C}_{3} \mathrm{H}_{8}$ (1), volume $40 \mathrm{~L}$, cooling unit (2), made by Thermo Electronic Corporation ("Neslab RTE 7"), cooling working spaces of pump, plunger-type gradient pump made by Thar Technology (3) and used for gas supply with a constant volume flow rate from 0.1 till $10 \mathrm{ml} / \mathrm{min}$, pressure regulating valve made by Go-Reg (BP66-1A11CJ0151). Initially, the propane-butane mixture, which is in the working space of the pump, should be cooled and condensed by the cooling unit, and then pushed the plunger of the pump in the system. Further, the plunger returns to its original position and working volume becomes to be filled with gas again. Due to the fact that the pump has two spaces, plungers which work in phase opposition, and due to the availability of the receiver (4) mounted in front of the system, constant discharge of propane-butane mixture is achieved. After receiver the mixture goes by tubes through heat exchanger (5) to extractor (6), which is pre-loaded with residual oil. During the extraction deasphaltizing the asphalt is accumulated at the bottom of the extractor. The extractor is a vessel of high pressure with a volume of $170 \mathrm{ml}$. Liquid solution of diasphaltizate in propane-butane mixture, which is draw out from the extractor (upper part) and passes through the heat exchanger (7), goes to the impregnation vessel (8), which is already operating under supercritical parameters of above mentioned solution, which is provided primarily due to the heat exchanger (7) and to a lesser degree due to adjustment valve after impregnation vessel. Thus the crushed stone impregnation in impregnation vessel is carried out under supercritical propane-butane solution of deasphaltizate. In addition to above it is necessary to mention that it is the case of dynamic impregnation, during which the process is continuous, as well as material deposition of impregnation in porous structure. This settlement, caused by decrease of dissolving capacity of propane-butane mixture, is realized not due to sudden one-time release of pressure as it is

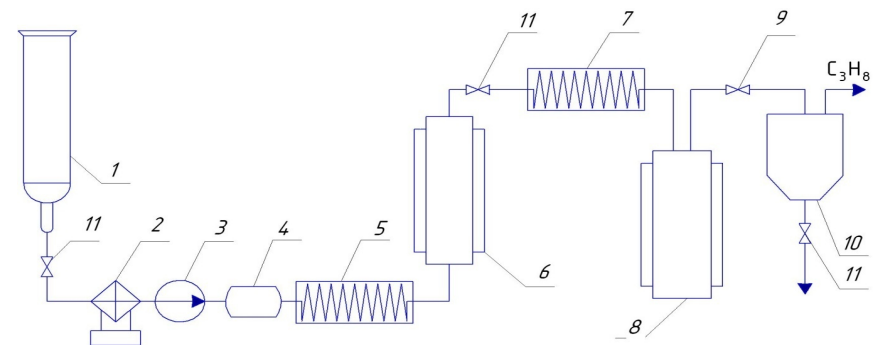

Figure 8. Complex experimental set of crushed stone impregnation by mesh of residual oil: 1 -baloon with $\mathrm{C}_{3} \mathrm{H}_{8} ; 2$ - cooling unit; 3-pump; 4-receiver; 5-heat exchanger; 6- extractor; 7-heat exchanger; 8-heated vessel for impregnation; 9-throttle valve; 10 - heated separator; 11 -throttle.

Table 1. Quantity chemical analysis of crushed limestone composition mesh size $20-40 \mu \mathrm{m}$.

\begin{tabular}{ccccccccc}
\hline & \multicolumn{7}{c}{ Content in \% on abs.dry test portion } \\
\cline { 2 - 8 } No. & $\mathrm{SiO}_{2}$ & $\mathrm{Al}_{2} \mathrm{O}_{3}$ & $\mathrm{Fe}_{2} \mathrm{O}_{3}$ & $\mathrm{CaO}$ & $\mathrm{MgO}$ & Losses & Insoluble precipitate & Organic matters \\
\hline 1. & 9.28 & 1.60 & 0.93 & 48.75 & 0.78 & 37.81 & 10.72 & Less than reference standard \\
2. & 9.39 & 1.66 & 0.91 & 48.26 & 0.78 & 37.68 & 10.99 & Less than reference standard \\
\hline
\end{tabular}


in static method, but because of increase of temperature which is realized on the spot of technological drawing between heat exchanger (7) and separator (10) including both. Thus, this is the case only when the pressure during the impregnation process is lower than pressure rating in the first crossover point on the chart of solvability of impregnating solution in propane/butane mixture, which is in SCF condition.

Appropriate temperatures in the extractor, impregnation chamber and separator are supported with electric heating jackets with stepwise adjustment.

\section{Results and Discussion}

The process of crushed stone impregnation with deasphaltizate comes to the following technological processes: extraction of deasphaltizate (oil hydrocarbons) with liquid propane from the heavy oil residue; impregnation of crushed stone with deasphaltizate under supercritical parameters of propane-butane mixture; regeneration of propane-butane mixture and return of it to recycle.

Operating parameters of providing complex process are given in Table 2.

Vent and content of deasphaltizate are defined by the nature of solvent, content of raw material, correlation of "extragent/raw material" and operating parameters of providing extraction process.

The asphalt, received during deasphaltization of oil residue with propane-butane mixture, has low content of satisfied hydrocarbon, high temperature of malaxation and critical content of asphalt pitch.

The asphalts have high density. High value of temperature of melting and cocking properties of asphalt is connected with great content in it of asphalt pitch. Due to that asphalt cements from them can be made by simple compounding of asphalt and initial axial oil [36].

Figure 9 shows comparison of deasphaltizate and asphalt spectra.

Maximum output of deasphaltizate corresponds to condition No. 1 (Table 2), providing of extraction process. It is known [36], that with increase of deasphaltizate output, in its structure increases content of ressin, sulfur and metals. At the same time, as shown on Figure 9, the sulfur and metals are preferably concentrated in the asphalt.

Table 3 shows results of chemical analysis about content of $\mathrm{V}$ in asphalt.

The influence of SCF impregnation process conditionson quality of crushed stone impregnation is shown on photos given in Figure 10.

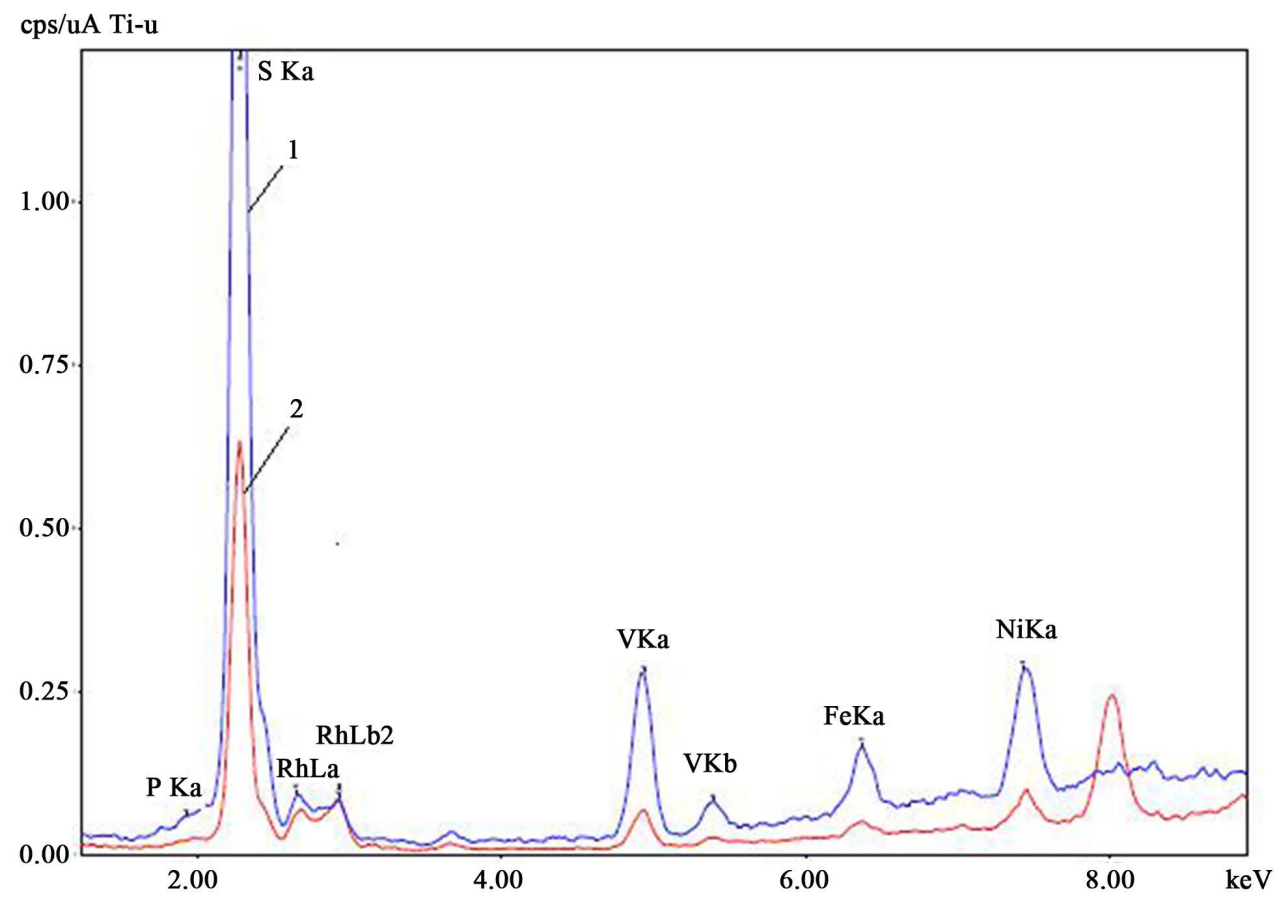

Figure 9. Deasphaltizate (2) and asphalt (1) spectra, received on first stage of complex process (conditions No. 1 in Table 2). 


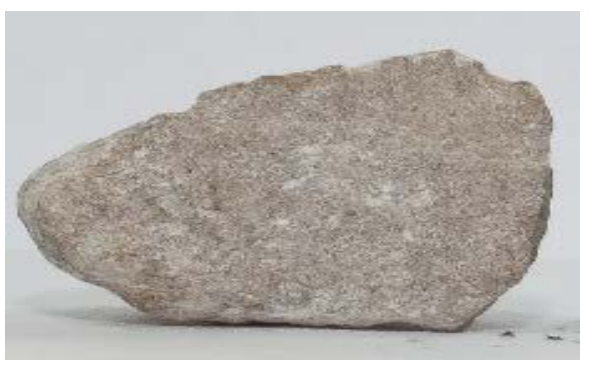

(a)

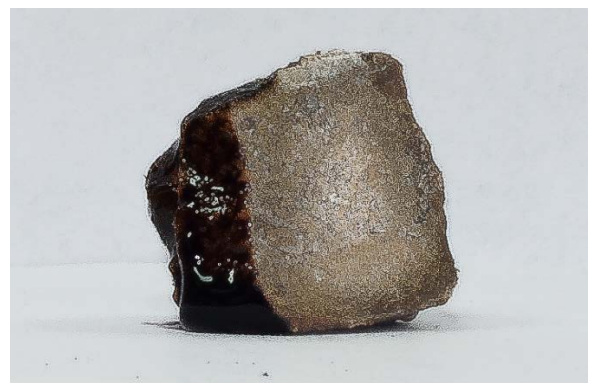

(c)

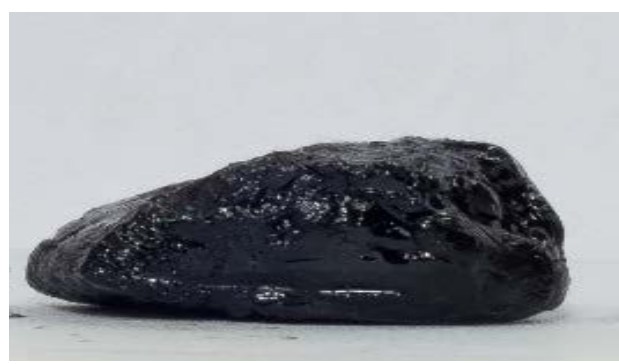

(b)

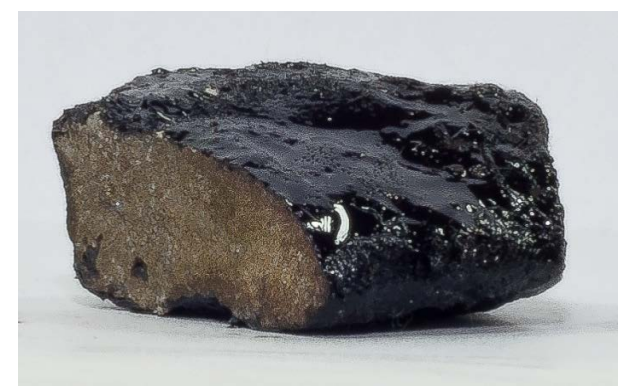

(d)

Figure 10. Photos of crushed stone samples: (a) Source sample; (b) Outer look of crushed stone sample after impregnation process; (c) Sample piece after impregnation in conditions No. 1 (Table 2); (d) Sample piece after impregnation in conditions No. 4 (Table 2).

Table 2. Operating parameters of providing complex process.

\begin{tabular}{|c|c|c|c|c|c|c|}
\hline $\begin{array}{l}\text { No. of operating } \\
\text { condition }\end{array}$ & $\begin{array}{l}\text { Pextraction, } \\
\text { Mpa }\end{array}$ & $\begin{array}{l}\mathrm{T}_{\text {extraction, }} \\
{ }^{\circ} \mathrm{C}\end{array}$ & $\begin{array}{l}\text { Pimpregnation, } \\
\text { МПа }\end{array}$ & ${ }^{\mathrm{T}_{\text {impregnation }}} \mathrm{C}$ & $\begin{array}{c}\text { Mass ratio } \\
\text { "extractant:oil residue" }\end{array}$ & $\begin{array}{c}\text { Vent of } \\
\text { deasphaltizate, \% }\end{array}$ \\
\hline 1 & 4.5 & 85 & 4.5 & 85 & $2: 1$ & 66 \\
\hline 2 & 4.5 & 85 & 4.5 & 138 & $1.5: 1$ & 54 \\
\hline 3 & 6.0 & 85 & 7.0 & 138 & $2: 1$ & 65.4 \\
\hline 4 & 7.0 & 85 & 7.0 & 138 & $1.5: 1$ & 52 \\
\hline 5 & 7.0 & 85 & 7.0 & 138 & $1: 1$ & 42 \\
\hline
\end{tabular}

Table 3. Results of chemical analysis about V content in asphalt for a sample, received under conditions No. 1 (Table 2).

\begin{tabular}{ccc}
\hline & Content & \\
\hline Vin ash & Ash content \\
\hline $23.4 \mathrm{mg} / \mathrm{kg}$ & $0.34 \%$ \\
\hline
\end{tabular}

Homogeneous deasphaltizate shell formed on the surface of the stone after the impregnation process (see Figures 10(b)-(d)), has good hydrophobic and adhesive properties. The latter has its force if applied to the asphalt coat material, which traditionally placed on the surface of crushed-stone layer during pavement forming up. Water absorption of the crushed stone sample is $0.24 \%$.

However, during road construction process and during first years in service, crushed stone fractionizes intensively, whereby its inner part becomes bare. In case of impregnation with the traditional approach, this part usually stays untreated, it causes increasing of water uptake of the material and deterioration of its physical and mechanical properties. One of the solutions to this problem is a pass-through and uniform impregnation of crushed stone.

Impregnation of crushed stone with liquid solution of deasphaltizate in propane-butane mixture (condition No. 1 in Table 2) provides peripheral preferably the so-called “crusted” impregnation (see Figure 10(c)). In the case 
of transfer of propane-butane mixture in a SCF state (conditions No. 2 - 5 in Table 2) impregnating of the crushed stone with deasphatizate is appears as uniform and "pass-through" (see Figure 10(d)).

Table 4 shows the physical and mechanical properties of the original and impregnated samples of crushed stone, evaluated under GOST techniques [37].

Indicators of water absorption determined after the crushing of initial and impregnated samples of crushed stone. As we can see, the rate of water absorption of the sample subjected to liquid impregnation (condition No. 1 in Table 2) does not differ from the rate obtained for the initial sample of crushed stone, due to the inner part impregnation absence in this sample. In the case of impregnation of the crushed stone with a deasphaltizate solution and propane-butane mixture in a SCF state (conditions No. 2 and No. 4 in Table 2), the water absorption prosperities of the samples decreases significantly.

In order to do identification, and some other qualitative indicators of the impregnation the structures of initial and treated samples were researched (the condition No. 4 in Table 2), for this reason appropriate cross-sectional views were prepared. (see Figure 11).

Description of cross-sectional view of initial crushed stone sample: limestone organogenic-detrital, with cloggy formations. Outlook of the basic mass formed up by large (up to $3 \mathrm{~mm}$ ) shells, scattered throughout the area of the section. Cloggy formations are located between these boundaries sizes $0.04-0.2 \mathrm{~mm}$, and smaller remnants of fauna. All this mass is cemented by fine-grained calcite. The reaction of Alizarin is positive. The grain size of calcite reaches $0.15 \mathrm{~mm}$. The pores constitute about $3 \%-5 \%$ of the total weight, and their sizes reach $0.15 \mathrm{~mm}$. Outlines of pores are isometric and angular. Pores partially filled with grains of gypsum.

Description of the cross-section view of crushed stone sample: treatedorganogenic-detrital limestones, cloggy. Up to $30 \%$ of the thin section is occupied by large $(1.0-1.5 \mathrm{~cm})$ valves of shells. The remaining section area consists of cloggy clay-carbonate formations. These formations are coupled via fine-grained poor argillo-calcite. Cloggy formations dimensions vary in the range from $0.05 \mathrm{~mm}$ to $0.24 \mathrm{~mm}$. The porosity is about $3 \%$. Pores have rounded and angular shapes. Their dimensions vary from $0.1 \mathrm{~mm}$ to $0.2 \mathrm{~mm}$. The walls of the pores covered by a film of oil-product, less often pores are filled with it. The breed has slightly brownish color of the total mass. Up to $30 \%$ of cloggy formations are impregnated by oil-products or have a rim of oil-products. Area of the road stone breed, which presented by crystalline calcite, remained unchanged. Penetration of oil-products is observed in the weak areas of the breed. Closer to treated surface the increasing of the amount of cloggy blobs reaches $50 \%$. In UV the poor luminescence of the treated zones could be noticed.

The proposed technology has the originality for the patent [38].

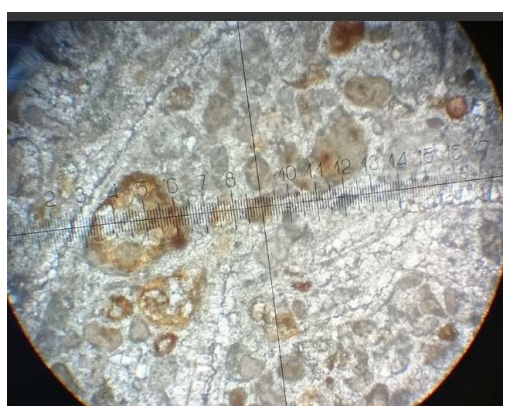

(a)

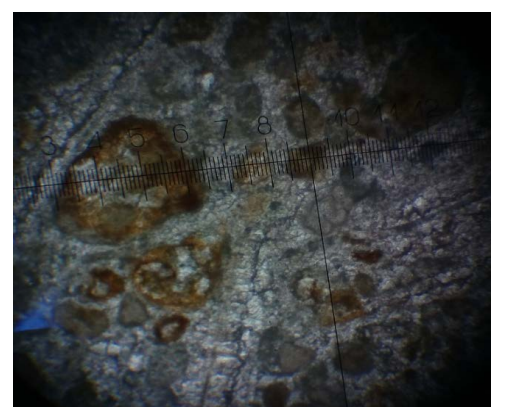

(b)

Figure 11. Photos of sample piece of crushed stone: (a) Source; (b) Treated.

Table 4. Physical and mechanical properties of the original and impregnated samples of crushed stone.

\begin{tabular}{|c|c|c|c|c|c|c|c|}
\hline \multirow{2}{*}{$\begin{array}{l}\text { No. of operating } \\
\text { condition }\end{array}$} & \multirow{2}{*}{$\begin{array}{l}\text { Fraction, } \\
\text { mm }\end{array}$} & \multirow{2}{*}{$\begin{array}{l}\text { True density, } \\
\mathrm{g} / \mathrm{cm}^{3}\end{array}$} & \multirow{2}{*}{$\begin{array}{l}\text { Average density, } \\
\mathrm{g} / \mathrm{cm}^{3}\end{array}$} & \multirow[b]{2}{*}{ Sponginess, \% } & \multirow{2}{*}{$\begin{array}{c}\text { Water uptake, } \\
\%\end{array}$} & \multicolumn{2}{|c|}{ Crushability rate, \%/grade } \\
\hline & & & & & & $\begin{array}{l}\text { In dry } \\
\text { consistence }\end{array}$ & $\begin{array}{l}\text { Hydro-saturated } \\
\text { consistence }\end{array}$ \\
\hline Initial sample & $20-40$ & 2.7 & 2.36 & 12.6 & 3.6 & $16.4 / 600$ & $17.1 / 600$ \\
\hline 1 & $20-40$ & - & - & - & 3.6 & - & - \\
\hline 2 & $20-40$ & - & - & - & 0.95 & - & - \\
\hline 4 & $20-40$ & 2.69 & 2.29 & 14.9 & 0.54 & $16.4 / 600$ & $16.9 / 600$ \\
\hline
\end{tabular}




\section{Conclusions}

An efficient technology of impregnation of carbonate crushed stone by oil-product based on using SCF-impregnation process with propane/butane solvent was developed. Regular impregnation throughout the volume of crushed stone sample is achieved.

By the nature of the penetration of oil-products in the samples of crushed stone, the aphanitic areas of breed with impure of clay matter are undergoes for treatment better. At the same time, zones of well-developed porosity weakened sections of the breed are involved.

As a result of the appliance of proposed technology, the humidity of the treated crushed stones samples decreased down to $0.54 \%$.

\section{Acknowledgements}

This paper has been executed with financial support by the Russian Minesterstva Education. Agreement No. 14.574.21.0085. Unique identifier for Applied Scientific Research RFMEFI57414X0085.

\section{References}

[1] Salihov, M.G., Bashirov, D.M., Gatiyatullin, M.H., Baronova, L.G. and Pushkin, E.A. (2001) Method of Preparation of Black Gravel. R.F. Patent No. 2200717.

[2] Gaidar, S.M., Konova, M.M. and Gromov, E.V. (2011) Method of Preparation of Black Gravel. R.F. Patent No. 2461522.

[3] Solovyov, M.V., Hozin, V.G. and Fomin, A.Y. (2013) Hardening of Road Stone Materials Molten Sulfur. News KAFU, 2, 263-267.

[4] Muhlënov, I.P., Dopkina, E.I., Deryuzhina, V.I. and Soroko, V.E. (1989) Tehnolologiy Acatalysts. Leningrad, Ed., Chemistry, $272 \mathrm{p}$.

[5] Asplund, S. (1996) Coke Formation and Its Effect on Internal Mass Transfer and Selectivity in Pd-Catalised Acetylene Hydrogenation. Journal of Catalysis, 158, 267-278. http://dx.doi.org/10.1006/jcat.1996.0026

[6] Bilalov, T.R. and Gumerov, F.M. (2011) The Manufacturing Processes and Catalyst Regeneration/Thermodynamic Basis of Production Processes and Regeneration of Palladium Catalysts Using Sverhkritiches-One Dioxide. LAP LAMBERT Academic Publishing GmbH \& Co. KG., Dudweiler Landstr., Germany, 153 p.

[7] Gumerov, F.M., Sabirzyanov, A.N. and Gumerova, G.I. (2000) Sub- and Supercritical Fluids in Polymer. Science, Kazan, 328 p.

[8] Bilalov, T.R., Gumerov, F.M., Gabitov, F.R., Fyodorov, G.I., Kharlampidi, K.E. and Sagdeev, A.A. (2009) Supercritical Carbon Dioxide Assisted Synthesis and Regeneration of Palladium Catalyst. Supercritical Fluids: Theory and Practice, 4, 34-52.

[9] Chernyshev, A.K., Gumerov, F.M. and Tsvetinsky, G.N. (2013) Carbon Dioxide. Galley Print, Moscow, 903 p.

[10] Garrido, G.I., Patcas, F.C., Upper, G., Turk, M., Yilmaz, S. and Kraushaar-Czarnetzki, B. (2008) Supercritical Deposition of Pt on $\mathrm{SnO}_{2}$-Coated $\mathrm{Al}_{2} \mathrm{O}_{3}$ Foams: Phase Behaviour and Catalytic Performance. Applied Catalysis A: General, 338, 58-65. http://dx.doi.org/10.1016/j.apcata.2007.12.019

[11] Liao, S.K. and Chang, P.S. (2012) Literatures on Dyeing Technique of Supercritical Fluid Carbon Dioxide. American Journal of Analytical Chemistry, 3, 923-930. http://dx.doi.org/10.4236/ajac.2012.312A122

[12] van der Kraan, M., Fernandez, M.V. and Woerlee, G.F. (2007) Dyeing of Natural and Synthetic Textiles in Supercritical Carbon Dioxide with Disperse Reactive Dyes. The Journal of Supercritical Fluids, 40, 470-476. http://dx.doi.org/10.1016/j.supflu.2006.07.019

[13] Guzel, B. and Akgerman, A. (2000) Mordant Dyeing of Wool by Supercritical Processing. Journal of Supercritical Fluids, 18, 247-252. http://dx.doi.org/10.1016/S0896-8446(00)00065-6

[14] Gastiger, M., van Oost, H., Eymard, P. and Masson, D. (1995) Impregnation des bois en phase supercritique in Fluidessupercritiques et materiaux. AIPFS, Publ., Nancy, 301-340.

[15] Lucas, S., Gonzalez, E., Calvo, M.P., Palencia, C., Alonso, E. and Cocero, M.J. (2007) Supercritical $\mathrm{CO}_{2}$ Impregnation of Radiata Pine with Organic Fungicides. Effect of Operating Conditions and Two-Parameters Modeling. Journal of Supercritical Fluids, 40, 462-469. http://dx.doi.org/10.1016/j.supflu.2006.08.003

[16] Iversen, S.B., Larsen, T., Henriksen, O. and Felsvang, K. (2003) The World’s First Commercial Supercritical Wood Treatement Plant. Proceedings of the 6th International Symposium on Supercritical Fluids, Versailles, 28-30 April 2003, 445-450. 
[17] Ikonnikov, V.K., Dobrodskaya, T.V., Romaschenkova, N.D., Sirotin, S.A., Dobrusina, S.A. and Podgornaja, N.I. (2010) Development of Technology for Mass Media Processing Paper-Based Using the Carbon Dioxide to Ensure Their Long-Term Preservation. Supercritical Fluids, Theory and Practice, 5, 43-59.

[18] Fernandes, J., Kjellow, A.W. and Henriksen, O. (2012) Modeling and Optimization of the Supercritical Wood Impregnation Process: Focus on Pressure and Temperature. Proceedings of the 10th International Symposium on Supercritical Fluids, San Francisco, 13-16 May 2012.

[19] Cansell, F. and Petitet, J.P. (1995) Fluidessupercritiques et materiaux. LIMHP CNRS, Paris, 327 p.

[20] Garrabos, Y., Le Neindre, B., Subra, P., Cansell, F. and Pommier, C. (1992) Fluides critiques et gravite, fluides supercritiques et materiaux. Annales de Chimie, 17, 55-90.

[21] Bork, M. (1998) Supercritical Fluid Dyeing of Synthetic Fibres. Proceeding of the 5th Meeting and Natural Products Processing, Nice, 23-25 March 1998, 387-391.

[22] Shim, J.J., Choi, J.H., Ju, J.H., Son, B.K., Ahn, J.M., Kim, B.H. and Kim, K.S. (2003) Dyeing of Polyester, Aramid, and Polypropylene Fibers in Supercritical $\mathrm{CO}_{2}$. Proceedings of the 6th International Symposium on Supercritical Fluids, Versailles, 28-30 April 2003.

[23] Bach, E., Schmidt, A., Cleve, E. and Schollmeyer, E. (2003) Treatement of Textiles in $\mathrm{CO}_{2}$-Potentialities and Limitations. Proceedings of the 6th International Symposium on Supercritical Fluids, Versailles, 28-30 April 2003.

[24] Kay, W.B. (1970) Vapor-Liquid Equilibrium Relations of Binary Systems. The Propane-n-Alkane Systems. n-Butane and n-Pentane. Journal of Chemical and Engineering Data, 15, 46-52. http://dx.doi.org/10.1021/je60044a026

[25] Beránek, P. and Wichterle, I. (1981) Vapour-Liquid Equilibria in the Propane-n-Butane System at High Pressures. Fluid Phase Equilibria, 6, 279-282. http://dx.doi.org/10.1016/0378-3812(81)85010-8

[26] Juntarachat, N., Bello, S., Privat, R. and Jaubert, J.N. (2013) Validation of a New Apparatus Using the Dynamic for Determining the Critical Properties of Binary Gas/Gas Mixtures. Journal of Chemical and Engineering Data, 58, 671676. http://dx.doi.org/10.1021/je301209u

[27] State Standard (GOST) 20448-90. Liquefied Hydrocarbon Gases Fuel for Domestic Consumption.

[28] Hansen, C.M. (2000) Hansen Solubility Parameters. CRC Press, London, 205 p.

[29] Gupta, R.B. and Shim, J.J. (2007) Solubility in Supercritical Carbon Dioxide. CRC Press, Boca Raton, 909 p.

[30] Amirhanov, D.G., Gumerov, F.M., Sagdeev, A.A. and Galimov, A.T. (2014) Solutes in the Supercritical Fluid Media. Otechestvo, Kazan, 264 p.

[31] Popov, V.K. (2013) Physico-Chemical Processes in Supercritical Fluids and Functionalization of Materials. Ph.D. Dissertation, MSU, 78 p.

[32] McHugh, M.A. and Krukonis, V.J. (1994) Supercritical Fluids Extraction: Principles and Practice. 2nd Edition, Butterworth-Heinemann, Oxford, 507 p.

[33] Mukhopadhyay, M. (2000) Natural Extracts Using Supercritical Carbon Dioxide. CRC Press, Boca Raton, 339 p. http://dx.doi.org/10.1201/9781420041699

[34] State Standard (GOST) 8267-93. Rubble and Gravel from Dense Rocks for Construction Work. Specifications.

[35] A Method of Producing Non-Oxidized Bitumen. RF Patent No. 2371468.

[36] Sultans, F.M. and Khairutdinov, I.R. (2001) Modern Processes of Propane and Propane-Butane Deasphalting. Refining and Petrochemicals: Coll. Nauchn. Works IPNHP AN RB, 51-56.

[37] State Standard (GOST) 8269.0-97. Rubble and Gravel from Dense Rocks and Industrial Waste Products for the Construction Work. Methods for Physical and Mechanical Tests.

[38] Patent Application No. 2014118199/03. 
Scientific Research Publishing (SCIRP) is one of the largest Open Access journal publishers. It is currently publishing more than 200 open access, online, peer-reviewed journals covering a wide range of academic disciplines. SCIRP serves the worldwide academic communities and contributes to the progress and application of science with its publication.

Other selected journals from SCIRP are listed as below. Submit your manuscript to us via either submit@scirp.org or Online Submission Portal.
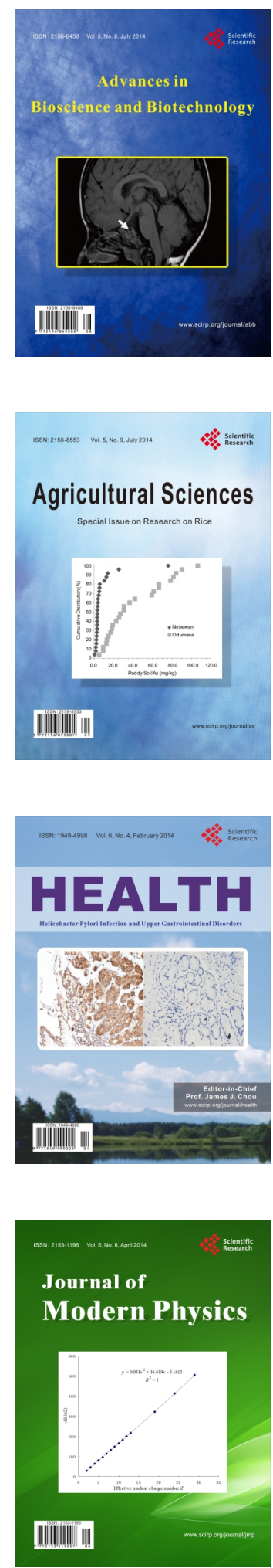
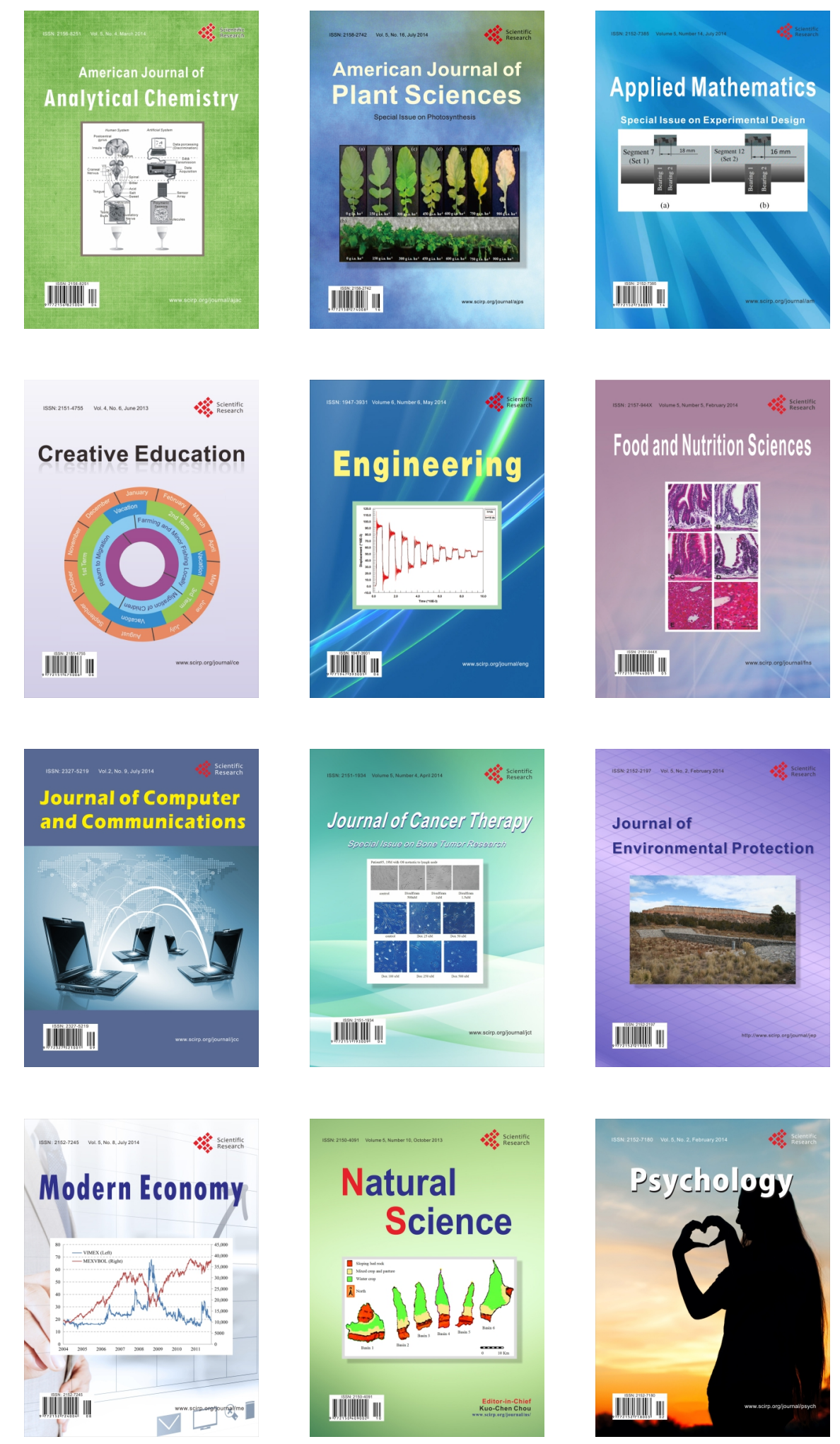